\section{Sleep Quality in Women with Breast Cancer: an Integrative Review

Thalyta Cristina Mansano-Schlosser ${ }^{1}$, Maria Filomena Ceolim 1 , Teresa D Valerio ${ }^{2}$

1 Faculty of Nursing, Campinas State University, São Paulo, Brazil.

2 Mennonite College of Nursing, Illinois State University, Ilinois, United States.

Background: Sleep disturbances are a chronic and challenging problem in cancer patients, often associated with multiple factors such as depression, anxiety, fatigue and pain.

Aim: The purpose of this integrative review is to evaluate the literature on sleep quality in women with breast cancer and the influence that poor sleep quality has on health.

Methods: Between 2009 and 2016, a search of PubMed, CINAHL, PsycINFO, Cochrane and Joanna Briggs databases with the descriptors sleep quality and breast cancer resulted in 27 studies that met the review criteria. The review questions were: How is the sleep quality in women with breast cancer? What health issues are associated with poor sleep quality in women with breast cancer?

Results: Findings support the presence of poor sleep quality in many women with breast cancer, before, during and after treatment associated with health issues.

Conclusions: Sleep disruptions are associated with breast cancer in woman, and affects their overall health. It is essential for nurses to identify sleep disorders and their impact on the health and quality of life of women with breast cancer. A deeper understanding of sleep quality in women with breast cancer can increase cancer nurses' skill in caring for their patients.

\section{Introduction and Background}

It is estimated that until 2020, the number of new cases of cancer per year will be about 15 million, of which about $60 \%$ will occur in developing countries. [1] Breast cancer is the second most frequent
Contact information:

Thalyta Cristina Mansano-Schlosser.

Address: Tessalia Vieira de Camargo 126, Brazil.

”- mansanothalyta@gmail.com

\section{Keywords}

Sleep Quality, Breast Cancer, Nursing. 
type of cancer in the world, and the most common cancer in women [1]. During 2010, in the United States, over 207,000 women were diagnosed with breast cancer [2].

Sleep disturbances occur in all types of cancer patients, and are associated with multiple factors such as depression, anxiety, treatment (e.g., chemotherapy radiation and surgery), cancer treatment-induced hot flashes, pain, fatigue and changes in biological rhythms [3]. Most studies do not consider whether sleep changes are associated with baseline sleep quality, baseline mental and physical health, demographic and clinical variables. Such associations might lead clinicians to target those at high risk for sleep problems [4].

An important study showed that better sleep efficiency was found to predict a significant reduction in overall mortality [5]. Additional research is needed to determine if beginning treatment of these symptoms before the start of chemotherapy will minimize symptom severity over time [6].

Sleep problems occur in many patients with cancer resulting in sleep deprivation that may affect their immunological status. Sleep deprivation produces a stress reaction in the body, being immunologically best characterized as an increase in leukocyte and neutrophil count, and in serum C-reactive protein rates. An experimental study conducted with healthy subjects showed that a single night of sleep deprivation is sufficient to cause these increases that return to baseline only with ten hours of recovery sleep. Cancer patients experiencing chronic sleep loss may be more vulnerable to these immunological changes because of the obstacles in obtaining sufficient recovery sleep, thus mounting an exacerbated and sustained inflammatory response [7].

Furthermore, Liu et al [8] reports a longitudinal relationship between fatigue, sleep parameters, and inflammation in breast cancer patients. These authors found that changes in reports of sleep quality were significantly associated with a decrease in circulating levels of IL-1RA. Additionally, there are changes in fatigue and sleep quality that were sig- nificantly associated with an increase in circulating levels of IL-6, and the relationship between sleep quality and IL- 6 was likely driven by fatigue.

When sleep disturbances become chronic, nurses need to make recommendations and referrals [9]. Because the sleep disturbances are common among breast cancer survivors, even after completion of active cancer treatment [10].

In a study aimed to associate breast cancer symptoms with sleep quality, [11] researchers found poor sleep quality present in $85 \%$ of women. A followup of those women, 2 to 7 months after baseline, revealed that $20 \%$ of those who reported poor sleep quality had worsening of clinical symptoms and $8 \%$ died $[11,7]$ The recognition that poor sleep quality may represent a prognostic factor in cancer patients should encourage nurses and other health professionals to give special attention to this important aspect of routine life $[4,12]$

\section{Methods}

\section{Review Questions}

The purpose of this review is to evaluate the scientific literature on sleep quality in women with breast cancer, and to assist nurses with understanding the potential health effect of poor sleep quality. The review questions are:

1) How is the sleep quality in women with breast cancer?

2) What health issues are associate with poor sleep quality in women with breast cancer?

\section{Search Criteria}

The population of concern is women (18 years or older), diagnosed with any type of breast cancer, and who are undergoing any treatment. Additional inclusion criteria are full-text articles, published in the last eight years (2009-2016), and in English. The primary outcome measure of interest is sleep quality including sleep, sleep duration, sleep disturbance, insomnia, and circadian-rhythms. This review con- 
siders both experimental and epidemiological study designs including randomized controlled trials, non-randomized controlled trials, quasi-experimental, before and after studies, prospective and retrospective cohort studies, case control studies and analytical cross sectional studies.

\section{Search Strategy}

An initial search of PubMed, CINAHL, PsycINFO, Cochrane database of systematic reviews and Joanna Briggs databases was undertaken. The title, abstract, and keywords of the articles were reviewed for relevance to the inclusion criteria. The following combinations of keywords were used in the search; sleep quality (sleep quality analysis, sleep quality assessment, sleep quality characteristics, sleep quality evaluation, sleep quality disturbance) and breast cancer (breast neoplasm, breast cancer symptoms, breast cancer fibroblast, breast cancer experimental).
Data collection was performed utilizing an instrument to identify the publication (main authors, year of publication), research purpose, methodological characteristics (design, sample, and instruments), and findings with conclusions on sleep quality and associated health issues.

\section{Results}

We selected 27 studies for review from an initial search in which 634 articles were found as outlined in the Figure 1.

Of the 634 articles found in the databases searched, we retrieved 27 articles that met the inclusion criteria as outlined in the Table 1.

Levels of Evidence by the Joanna Briggs Institute (JBI) Levels of Evidence and Grades of Recommendation Working on Table 2. [13].

Figure 1: Study selection process and results.

\section{Keywords. Sleep quality and breast cancer}

Additional limits: 2009-2016, women, full text, English
Articles excluded due to no data on the review questions


Table 1. Summary of Research on Sleep Quality and Associated Health Issues in Women with Breast Cancer.

\begin{tabular}{|c|c|c|c|c|c|}
\hline Authors & Year Research Purpose & Design & Sample & Instruments & Finding / Conclusions on Sleep QualityAssociated Health Issues \\
\hline Berger & $\begin{array}{l}\text { (2009) Level 1.a. To determine } \\
\text { whether sleep quality and fatigue } \\
\text { are associated with breast cancer } \\
\text { adjuvant chemotherapy treatments } \\
\text { and can be improved with } \\
\text { behavioral therapy (BT) including } \\
\text { modified stimulus control, modified } \\
\text { sleep restriction, relaxation therapy, } \\
\text { and sleep hygiene }\end{array}$ & $\begin{array}{l}\text { Randomized- } \\
\text { controlled trial based } \\
\text { on Piper Integrated } \\
\text { Fatigue Model } \\
\text {-Longitudinal }\end{array}$ & $\begin{array}{l}219 \text { females stage, } \\
\text { I-IIIA breast cancer, } \\
\text {-BT participants had } \\
\text { an Individualized Sleep } \\
\text { Promotion Plan (ISPP), } \\
\text {-Controls received healthy } \\
\text { eating information (HEC) }\end{array}$ & $\begin{array}{l}\text { Pittsburgh Sleep Quality } \\
\text { Index (PSQI), sleep diary and } \\
\text { actigraphy (48 hrs prior to initial } \\
\text { treatment, } 7 \text { days/nights at each } \\
\text { treatment, } 7 \text { days/nights } 30 \\
\text { days after last treatment), Piper } \\
\text { Fatigue Scale (PFS), Symptoms } \\
\text { Experience Scale (SES), Hospital } \\
\text { Anxiety and Depression Scale, } \\
\text { Medical Outcomes Study Short- } \\
\text { form General Health Survey }\end{array}$ & $\begin{array}{l}\text { Daily sleep diary and actigraphy } \\
\text { data revealed sleep near or within normal limits, except for number of } \\
\text { awakenings and longer wake after sleep onset } \\
\text { Participants reported mild Fatigue, poor sleep quality, normal anxiety and } \\
\text { depression levels and low physical functioning } \\
\text { Significant differences over time on all sleep variables obtained by diary } \\
\text { and actigraphy [all } P<.01] \\
\text { Changes in sleep quality (PSQI) in the groups over time [P =.003] } \\
\text { BT group showed improved sleep quality over time on sleep per diary and } \\
\text { actigraphy [less awakenings } \\
P=.032 \text { and P }=.03 \text {; higher efficiency P }=.027 \text { and total sleep time P }= \\
.09] \\
\text { Mean PSQI scores in both groups were greater than } 5 \text { but less than } 8 \text { at } \\
\text { all measurements, reflecting fairly poor sleep quality } \\
\text { Peri-and postmenopausal women in the HEC group rated poorer sleep } \\
\text { quality than ISPP group } \\
\text { Menopausal status when starting chemotherapy was associated with } \\
\text { differing patterns of poor sleep and hot flashes over time } \\
\text { Difficulty maintaining sleep was evident by higher than normal (2-6) } \\
\text { number of awakenings per night (6-12) Mean number of awakenings } \\
\text { varied significantly over time } P=.04-\text { Minutes awake after sleep onset per } \\
\text { night over time varied widely, and was higher than normal values }\end{array}$ \\
\hline Banthia & $\begin{array}{l}\text { (2009) Level 3.e. To examine age, } \\
\text { cancer stage, sleep quality and } \\
\text { depressed mood as predictors of } \\
\text { five dimensions of fatigue }\end{array}$ & Cross-sectional & $\begin{array}{l}70 \text { fatigued female breast } \\
\text { cancer survivors with } \\
\text { a minimum of } 5 \text { on the } \\
\text { Multidimensional Fatigue } \\
\text { Symptom Inventory-Short } \\
\text { Form (MFSI-SF) }\end{array}$ & $\begin{array}{l}\text { General fatigue scale, } \\
\text { MFSI-SF, PSQI, and Center } \\
\text { for Epidemiological Studies- } \\
\text { Depression Scale (CES-D) }\end{array}$ & $\begin{array}{l}\text { PSQI global score was significantly correlated with the CES-D total score } \\
\text { and all MFSI-SF subscales, except mental fatigue } \\
\text { Correlations of greatest magnitude were general [.44] and physical [.42] } \\
\text { fatigue } \\
\text { Simple bivariate relationships of the four predictors (age, cancer stage, } \\
\text { CES-D and PSQI Variables that had coefficients above an absolute value } \\
\text { of .33 were interpreted as strong predictors } \\
\text { Higher scores on the PSQI predicted membership in the higher fatigue } \\
\text { group for general and physical fatigue }\end{array}$ \\
\hline
\end{tabular}




\begin{tabular}{|c|c|c|c|c|c|}
\hline Authors & Year Research Purpose & Design & Sample & Instruments & Finding / Conclusions on Sleep QualityAssociated Health Issues \\
\hline Dirksen & $\begin{array}{l}\text { (2009). Level 1.b. To determine } \\
\text { if breast cancer survivors with } \\
\text { insomnia can be grouped according } \\
\text { to their level of fatigue }\end{array}$ & $\begin{array}{l}\text { Secondary data } \\
\text { analysis of baseline } \\
\text { data from a } \\
\text { randomized control } \\
\text { trial }\end{array}$ & $\begin{array}{l}86 \text { female breast cancer } \\
\text { survivors with insomnia }\end{array}$ & $\begin{array}{l}\text { Profile of Mood States Fatigue } \\
\text { (POMS F/I), Insomnia Severity } \\
\text { Index (ISI), State-Trait Anxiety } \\
\text { Inventory (STAI), CES-D }\end{array}$ & $\begin{array}{l}58(68 \%) \text { had clinically significant insomnia (ISI score }>15) 20(24 \%) \text { had } \\
\text { clinically significant level of depression (CES-D score }>16) \text { Significant } \\
\text { differences were also noted on anxiety, with the Restored and Tired } \\
\text { groups having a significantly lower level of state and trait anxiety } \\
\text { compared to the Exhausted group Exhausted group had a significantly } \\
\text { higher level of depression in comparison to the Tired and Restored groups }\end{array}$ \\
\hline Otte & $\begin{array}{l}\text { (2010) Level 3.d. To refine } \\
\text { knowledge regarding prevalence, } \\
\text { severity, and correlates of sleep- } \\
\text { wake disturbances in long-term } \\
\text { breast cancer survivors compared } \\
\text { to age-matched women without } \\
\text { breast cancer (WWC). }\end{array}$ & $\begin{array}{l}\text { Cross-sectional, } \\
\text { comparative, case- } \\
\text { controlled }\end{array}$ & $\begin{array}{l}246 \text { female breast cancer } \\
\text { survivors (BCS) and } 246 \\
\text { women without breast cancer } \\
\text { (WWC) }\end{array}$ & $\begin{array}{l}\text { RAND Physical Functioning-10 } \\
\text { (PF-10), PSQI, CES-D, Concerns } \\
\text { about Recurrence Scale (CARS), } \\
\text { Impact of Events Scale (IES) }\end{array}$ & $\begin{array}{l}\text { BCS had significantly more prevalent sleep-wake disturbances (65\%) } \\
\text { compared to WWC }(55 \%)[P<.05)] \\
\text { BCS had significantly higher PSQI global scores indicating poorer sleep } \\
\text { quality compared to WWC }[\mathrm{P}<.05] \\
\text { Significant correlates of poor sleep prevalence for BCS included hot } \\
\text { flashes, poor physical functioning, depressive symptoms and distress } \\
\text { WWC had higher impact of a life event reflected by higher mean scores } \\
\text { for the IES P }<.05\end{array}$ \\
\hline Thomas & $\begin{array}{l}\text { (2009) Level 3.e. To examine } \\
\text { changes in sleep and coping as a } \\
\text { predictor of sleep during radiation } \\
\text { therapy and over a } 6 \text { - month follow } \\
\text { up }\end{array}$ & Longitudinal & $\begin{array}{l}33 \text { women with breast } \\
\text { cancer }(B C) \text { and } 23 \text { men with } \\
\text { prostate cancer }(P C) \text { Self- } \\
\text { reported sleep was assessed } \\
\text { at eight time points before, } \\
\text { during, and after treatment }\end{array}$ & $\begin{array}{l}\text { Medical Outcomes Study Health } \\
\text { Survey (MOS), Sleep Scale (MOS- } \\
\text { Sleep), COPE Inventory (COPE- } \\
\text { brief), Cancer treatment-related } \\
\text { symptoms scales }\end{array}$ & $\begin{array}{l}B C \text { and } P C \text { patients reported the most sleep problems prior to and during } \\
\text { the early weeks of treatment }[\mathrm{P}<.05] \\
\text { Significant relationship between depressed mood and sleep latency over } \\
\text { time in a regression analysis. } \\
\text { On weeks when patients reported more depression, took longer to fall } \\
\text { asleep }[\mathrm{P}=.13]\end{array}$ \\
\hline Beck & $\begin{array}{l}\text { (2010) Level 1.b. To characterize } \\
\text { sleep quality and quantity prior to } \\
\text { and in the first } 3 \text { nights after initial } \\
\text { chemotherapy for breast cancer }\end{array}$ & $\begin{array}{l}\text { Secondary analysis } \\
\text { from two data sets }\end{array}$ & $\begin{array}{l}183 \text { women with breast } \\
\text { cancer }\end{array}$ & PSQI, actigraphy, MOS & $\begin{array}{l}65 \% \text { were poor sleepers, } 25.7 \% \text { had "fairly bad" or "very bad" overall } \\
\text { sleep quality on PSQI (Item 6) at baseline } \\
3 \text { nights of actigraphy recorded a wide range of sleep experience with an } \\
\text { average of } 10 \text { awakenings, first night sleep worst } \\
\text { Poor sleep at baseline had significantly lower [P<.001] physical (MOS } \\
\text { PCS) and mental (MOS MCS) health status }\end{array}$ \\
\hline Garrett & $\begin{array}{l}\text { (2011) Level 3.e. To evaluate for } \\
\text { differences in the occurrence rates } \\
\text { of sleep disturbances and fatigue }\end{array}$ & Cross-sectional & $\begin{array}{l}\text { Women with breast }(\mathrm{N}=78) \\
\text { and men with prostate }(\mathrm{N} \\
=82 \text { ) cancer }\end{array}$ & $\begin{array}{l}\text { PSQI, General Sleep Disturbance } \\
\text { Scale (GSDS), Lee Fatigue Scale } \\
\text { (LFS), actigraphy }\end{array}$ & $\begin{array}{l}\text { Breast cancer patients reported significantly longer sleep onset latency } \\
{[P=.02] \text {, significantly more sleep disturbances }[\mathrm{P}<.001] \text {, and significantly }} \\
\text { greater daytime dysfunction }[\mathrm{P}=.003] \\
\text { Mean } \mathrm{PSQ} \text { I global score was significantly higher in the patients with } \\
\text { breast cancer than prostate cancer }[\mathrm{P}=.08] \text {. }\end{array}$ \\
\hline
\end{tabular}




\section{Authors Year Research Purpose}

(2011) Level 1.b. To characterize

and compare disrupted sleep patterns in fatigued breast cancer patients receiving chemotherapy with postmenopausal women without a history of cancer

Alfano (2011). Level 3.e. To investigate patterns of sleepduration change across the early breast cancer survivorship period, demographic and clinical predictors, and relationships with subsequent cancer-related symptoms and health-related quality of life (HRQOL)

Mosher (2012) Level 3.e- To assess the and prevalence of distress among

DuHamel metastatic cancer patients using Distress Thermometer (DT)

fatigue and sleep measured both subjectively and objectively

\section{Design}

Secondary data

analysis from two

studies

Sample

30 fatigued female breast cancer (BC) chemotherapy outpatients and 32 non cancer postmenopausal women

Longitudinal: 6 months post-

572 female breast cancer diagnosis, 30 months post-diagnosis and

39 months post-

diagnosis

Cross-sectionaltelephone survey 1 week after DT

to assess anxiety, depressive symptoms, sleep problems, and

fatigue.

\section{Longitudinal}

\begin{abstract}
97women with newly diagnosed stage I-III breast cancer, scheduled to receive at least four 3-week cycles of chemotherapyData collected at 7 time points: before (baseline) and during the 3 weeks of cycle 1 through cycle 4 chemotherapy ( $\mathrm{C}=$ cycle and $\mathrm{W}=$ week)
\end{abstract} survivors

173 female metastatic breast. DT, PSQI, CES-D, Hospital Anxiety and Depression Scale, Functional Assessment of Chronic Illness Therapy Fatigue subscale, Karnofsky Performance Status Scale (KPS)

PSQI, actigraphy, MFSI-SF

iable Activity

Questionnaire, PFS, Perceived

Stress Scale (PSS), CARS, SF-36
Finding / Conclusions on Sleep QualityAssociated Health Issues

BC patients showed significant sleep difficulties; prolonged sleep onset latency $[\mathrm{M}=54.3, \mathrm{SD}=49.2$ minutes] and frequent nighttime awakenings, despite $40 \%$ of the patients using sleep medications three or more times a week

Compared to the non-cancer group, fatigued cancer patients reported significantly longer sleep latency $[P=.041]$, more use of sleep medications $[P=.06]$, and higher total PSQI scores $[P=.05]$

STAI scores did not differ between the two groups $[P=.88]$

-Mean total sleep time about 7 hours at each time point $[S D=1,2$; range for each 3.5-9]

$25 \%$ had sleep duration change over time; temporary (5.6\%), lateoccurring $(14 \%)$, or sustained $(5.9 \%)$

Sustained sleep changes were related to greater subsequent severity, affective, and sensory aspects of fatigue $[\mathrm{P}=$ all $<.01]$

$70 \%$ had PSQI scores greater than 5 [95\% $\mathrm{Cl}=59-79 \%]$, indicating significant decrements in sleep quality

$60 \%$ met the clinical cutoff (4) for probable distress on the DT

Younger women had higher levels of anxiety $[\mathrm{P}<.05]$, greater medical

comorbidities were associated with greater depressive symptoms $[P<.05]$, greater fatigue $[\mathrm{P}<.05]$, and poorer sleep quality $[\mathrm{P}<.05$

Mean PSQI scores indicated poor sleep quality at all 7 time points At baseline, $61 \%$ reported PSQI $>5$ and $32 \%$ PSQI $>8$; at the end of treatment (C4W33), 76\% PSOI $>5$ and $42 \%$ PSOI $>8$

Subjective sleep quality was poor at baseline and remained unchanged throughout treatment. There was a significant overall time effect $[\mathrm{P}<.001]$ for total sleep time

Significant negative correlations between total wake time during the day (WAKE) and MFSI-SF General [P = .03] and Physical [P = .05] subscale scores at C1W1, and significant positive correlation between WAKE and MFSI-SF Vigor subscale scores $[\mathrm{P}=.04]$ 


\begin{tabular}{|c|c|c|c|c|}
\hline Authors & Year Research Purpose & Design & Sample & Instruments \\
\hline Dhruva & $\begin{array}{l}\text { (2012) Level 3.e.To } \\
\text { examine how actigraphy } \\
\text { and self-report ratings } \\
\text { of sleep disturbance } \\
\text { changed over the course } \\
\text { of and following radiation } \\
\text { therapy (RT) }\end{array}$ & Longitudinal & $\begin{array}{l}73 \text { women with breast } \\
\text { cancer }\end{array}$ & $\begin{array}{l}\text { Actigraphy, GSDS, KPS scale, } \\
\text { LFS,CES-D, Spielberg State-Trait } \\
\text { Anxiety, Brief Pain Inventory }\end{array}$ \\
\hline Girschik & $\begin{array}{l}\text { (2013) Levels of } \\
\text { Evidence:3.d }\end{array}$ & $\begin{array}{l}\text { population-based } \\
\text { case-control study }\end{array}$ & $\begin{array}{l}\text { control: 1695, } \\
\text { Case:1133 }\end{array}$ & $\begin{array}{l}\text { a self-administered postal } \\
\text { questionnaire that contained } \\
\text { questions on demographic, } \\
\text { reproductive, and lifestyle } \\
\text { factors as well as sleep. The } \\
\text { domains of sleep investigated } \\
\text { were: usual duration of sleep } \\
\text { on workdays; usual duration } \\
\text { of sleep on nonworkdays; and } \\
\text { subjective sleep quality. }\end{array}$ \\
\hline $\begin{array}{l}\text { Aldridge- } \\
\text { Gerry }\end{array}$ & $\begin{array}{l}\text { (2013) Levels of } \\
\text { Evidence:3.e }\end{array}$ & observational & $\begin{array}{l}\text { Women with } \\
\text { metastatic breast } \\
\text { câncer MBC ( } N=103)\end{array}$ & $\begin{array}{l}3 \text { nights of polysomnography } \\
\text { (PSG). }\end{array}$ \\
\hline
\end{tabular}

$\begin{array}{ll}\text { Liu (2013) Levels of } & \text { Iongitudinal } \\ \text { Evidence:3.e } & \end{array}$

166 women with newly diagnosed stage Form Physical Component Scale |-||| breast. Câncer

\section{Finding / Conclusions on Sleep QualityAssociated Health Issues}

For actigraphy, $87 \%$ had an excessive number of awakenings, $46 \%$ had an abnorma

Wake After Sleep Onset (WASO), and 58\% had Total Seep Time (TST) below healthy adult values

More than $85 \%$ of the patients had high number of nighttime awakenings

Approximately $50 \%$ had abnormal WASO and total GSDS scores at the initiation of RT Comorbidity, evening fatigue, and depressive symptoms predicted baseline levels of subjective sleep disturbance, and depressive symptoms predicted the trajectory of subjective sleep disturbance

no association between

self-reported sleep duration on workdays and risk of breast cancer (for $<6$ hours, odd ratio $(\mathrm{OR})=1.05(95 \% \mathrm{Cl}: 0.82,1.33)$; for $6-7$ hours, $\mathrm{OR}=0.96(95 \% \mathrm{Cl}: 0.80,1.16)$; and for $>8$ hours, $\mathrm{OR}=1.10(95 \% \mathrm{Cl}: 0.87,1.39)$, compared with the reference category of 7-8 hours' sleep). In addition, we found no association between sleep duration on nonworkdays, subjective sleep quality, or combined duration and quality and risk of breast cancer. This study does not provide evidence to support an association between selfreported sleep duration or quality and the risk of breast cancer.

Women with $\mathrm{MBC}$ who reported more depressive symptoms had lighter sleep (e.g., stage 1 sleep; $P<.05)$, less slow-wave sleep (SWS) $(P<.05)$, and less rapid eye movement (REM) sleep $(P<.05)$. Single women had less total sleep time $(T S T)(P<.01)$, more wake after sleep onset (WASO) $(P<.05)$, worse sleep efficiency $(S E)(P<.05)$, lighter sleep (e.g., stage 1; $\mathrm{P}<.05)$, and less REM sleep $(\mathrm{P}<.05)$ than married women.

Women with MBC and greater symptoms of depression had increased light sleep and reduced SWS and REM,

Patients reported poor HRQOL and poor sleep quality before and during chemotherapy.

Short sleep time and long naps were recorded at both time points. The Mental Component score was related to reports of poor sleep but not to recorded sleep, worse Physical Component scores were associated with reports of poor sleep and less recorded nap time, suggesting sleep plays an important role in cancer patients' HRQOL. scores. Subjective sleep was assessed with the Pittsburgh Sleep Quality Index (PSQI):

objective sleep was measured with actigraphy. 


\begin{tabular}{|c|c|c|c|c|c|}
\hline Authors & Year Research Purpose & Design & Sample & Instruments & Finding / Conclusions on Sleep QualityAssociated Health Issues \\
\hline Tell & $\begin{array}{l}\text { (2014) Levels of } \\
\text { Evidence:3.e }\end{array}$ & Longitudinal & Women $(\mathrm{N}=130$, & $\begin{array}{l}\text { collected saliva } 5 \times / \text { day/2 days for cortisol; } \\
\text { Diaries;Multidimensional Fatigue Symptom } \\
\text { Inventory and the Pittsburg Sleep Quality } \\
\text { Inventory. }\end{array}$ & $\begin{array}{l}\text { Greater ongoing fatigue }(b=0.035, p=.032) \text {, or sleep disturbance } \\
(b=0.026, p=.006) \text { predicted a slower cortisol decline. } \\
\text { Longer sleep latency predicted both a greater cortisol linear decline } \\
\text { ( } b=-0.013, p<.001) \text {. } \\
\text { Both daily variations in sleep behaviors and ongoing sleep disturbance } \\
\text { and fatigue associated with a disrupted cortisol rhythm }\end{array}$ \\
\hline Garland & $\begin{array}{l}\text { (2014) Levels of } \\
\text { Evidence:3.d }\end{array}$ & case control & $\begin{array}{l}70 \text { women with moderate to severe } \\
\text { insomnia symptoms and a matched } \\
\text { comparison group of } 70 \text { women } \\
\text { without insomnia symptoms ( } n= \\
\text { 140). }\end{array}$ & $\begin{array}{l}\text { Insomnia Severity Index (ISI); The Hospital } \\
\text { Anxiety and Depression Scale (HADS) ;The } \\
\text { Brief Fatigue Inventory (BFI) }\end{array}$ & $\begin{array}{l}\text { Women with significant insomnia symptoms had higher levels of } \\
\text { unemployment compared to women without insomnia. TL (telomere } \\
\text { lengh) was positively skewed and shorter in the insomnia group. } \\
\text { Women with insomnia also reported significantly higher levels of } \\
\text { depression }(p<0.001) \text {, anxiety }(p<0.001) \text {, and fatigue }(p<0.001) \text {. }\end{array}$ \\
\hline Mao & $\begin{array}{l}\text { (2014) Levels of } \\
\text { Evidence:1.a }\end{array}$ & $\begin{array}{l}\text { randomized } \\
\text { Trial }\end{array}$ & $\begin{array}{l}67 \text { randomly assigned patients, of } \\
\text { an eight-week course of electro- } \\
\text { acupuncture (EA) as compared to } \\
\text { waitlist control (WLC) and sham } \\
\text { acupuncture }(S A) \text { in postmenopausal } \\
\text { women with breast cancer }\end{array}$ & $\begin{array}{l}\text { Brief Fatigue Inventory (BFI), Pittsburgh } \\
\text { Sleep Quality Index (PSQI), and Hospital } \\
\text { Anxiety and Depression Scale (HADS). }\end{array}$ & $\begin{array}{l}\text { baseline pain interference was associated with fatigue (Pearson } \\
\text { correlation coefficient } r=0.75, p<0.001) \text {, sleep disturbance }(r=0.38 \text {, } \\
p=0.0026) \text {, and depression }(r=0.58, p<0.001) \text {. } \\
\text { Compared to the WLC, EA produced significant improvement in fatigue } \\
\text { ( } p=0.0095) \text {, anxiety }(p=0.044) \text {, and depression ( } p=0.015) \\
\text { Compared to usual care, EA produced significant improvement in fatigue, } \\
\text { anxiety, and depression, whereas } S A \text { improved only depression in women } \\
\text { experiencing Al-related arthralgia. }\end{array}$ \\
\hline Palesh & $\begin{array}{l}\text { (2014) Levels of } \\
\text { Evidence:3.e }\end{array}$ & Longitudinal & among 97 women. & $\begin{array}{l}\text { wrist-worn actigraphy and sleep diaries for } \\
3 \text { days }\end{array}$ & $\begin{array}{l}\text { better sleep efficiency was found to predict a significant reduction } \\
\text { in overall mortality (hazard ratio [HR], } 0.96 ; 95 \% \text { confidence interval } \\
[\mathrm{CI}], 0.94-0.98 ; \mathrm{P}<0.001) \text { at median } 6 \text { y follow-up. This relationship } \\
\text { remained significant }(\mathrm{HR}, 0.94 ; 95 \% \mathrm{Cl}, 0.91-0.97 ; \mathrm{P}<0.001) \text { even } \\
\text { after adjusting for other known prognostic factors (age, estrogen } \\
\text { receptor status, cancer treatment, metastatic spread, cortisol levels, and } \\
\text { depression). } \\
\text { These findings show that better sleep efficiency and less sleep disruption } \\
\text { are significant independent prognostic factors in women with advanced } \\
\text { breast cancer. Further research is needed }\end{array}$ \\
\hline
\end{tabular}




\section{Authors}

Ancoli-

Israe

Year Research Purpose

(2014) Levels of Evidence:3.e

Design

Longitudinal

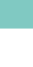

six

Sample stage I-III breast cancer (BC) scheduled to receive $\geq 4$ cycles of chemotherapy

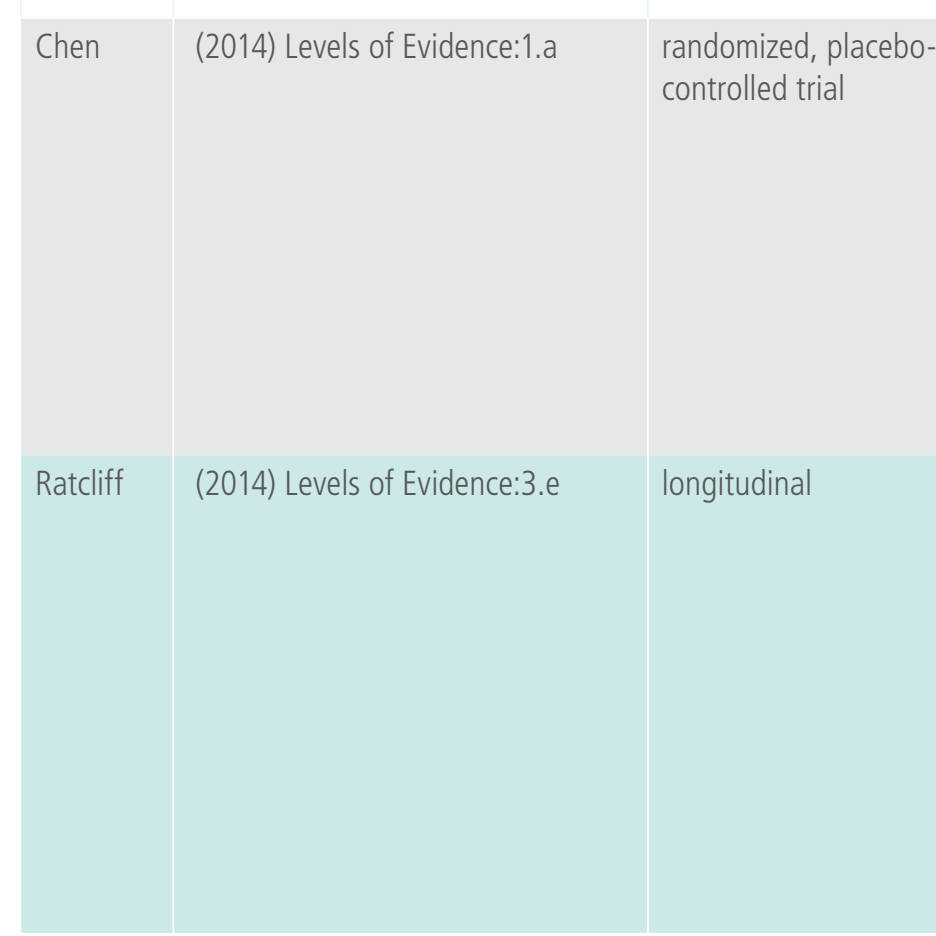

Twenty women undergoing $\mathrm{CT}$ for breast cancer

95 postmenopausal women with a prior history of stage 0-III breast cancer
Pittsburgh Sleep Quality Index (PSQI)and mood three times daily (morning, afternoon, and evening) via ecological momentary assessments (EMAs) using automated handheld computers.
Finding / Conclusions on Sleep QualityAssociated Health Issues

Compared to NC, BC had longer NAPTIME, worse sleep quality, more

fatigue, more depressive symptoms, more disrupted CARs and worse QoL at Baseline

Cycle-4, BC showed worse sleep, increased fatigue, more depressive symptoms, and more disrupted CARs compared to their own Baseline levels and to NC (all p's<0.05). By 1-year, BC's fatigue, depressive symptoms and QoL returned to Baseline levels but were still worse than those of NC, while NAPTIME and CARs did not differ from NC's Additional research is needed to determine if beginning treatment of these symptoms before the start of chemotherapy will minimize symptom severity over time.

Studies-Depression (CES-D).

CARs were derived from actigraphy.

Pittsburgh Sleep Quality Index (PSQI), Depression (CES-D), and the North Central Cancer TreatmentGroup (NCCTG) hot flash diary,

At baseline, $52 \%$ of participants reported poor sleep in the month prior to enrollment. Compared to subjects on placebo, subjects randomized to melatonin experienced significantly greater improvements in subjective sleep quality as measured by the PSQI, including domains on sleep quality, daytime dysfunction and total score.

Sleep disturbances are common among breast cancer survivors, even after completion of active cancer treatment. This is the first randomized placebo-controlled study among breast cancer survivors to demonstrate that melatonin was associated with an improvement in subjective sleep quality, without any significant adverse effects.

The results showed that disturbed sleep (PSQI score $\geq 5$ ) prior to CT infusion was associated with greater fatigue, and more negative and anxious mood throughout the 3 week CT cycle, and good pre-CT infusion sleep (PSQI score $<5$ ) buffered anxious mood in the first days following infusion.

No evening symptom or mood ratings were related to subsequent sleep quality.

These findings suggest that disturbed sleep before and after a CT infusion exacerbates fatigue, and negative, anxious, and drowsy mood during a CT cycle. Reducing sleep disturbance may be an important way to improve quality of life during chemotherapy. 


\begin{tabular}{|c|c|c|c|c|c|}
\hline Authors & Year Research Purpose & Design & Sample & Instruments & Finding / Conclusions on Sleep QualityAssociated Health Issues \\
\hline Vargas & (2014) Levels of Evidence:1. & intervention Trial & $\begin{array}{l}\text { Patients were randomized } \\
\text { to CBSM ( } n=120) \text { or a one- } \\
\text { day psychoeducation control } \\
\text { group }(n=120) \text {. }\end{array}$ & $\begin{array}{l}\text { Pittsburgh Sleep Quality Index } \\
\text { (PSQI) and Fatigue Symptom } \\
\text { Inventory were completed prior } \\
\text { to randomization and } 6 \text { and } \\
12 \text { months after the baseline } \\
\text { assignment }\end{array}$ & $\begin{array}{l}\text { In latent growth analyses, women in CBSM reported greater } \\
\text { improvements in PSQI sleep quality scores than controls, although there } \\
\text { were no significant differences between conditions on PSQI total scores } \\
\text { Future work may consider integrating sleep and fatigue content into stress } \\
\text { management interventions for women with early-stage breast cancer. }\end{array}$ \\
\hline Roscoe & (2014) Levels of Evidence:1* & randomized trial & 96 cancer survivors & $\begin{array}{l}\text { Insomnia Severity Index and } \\
\text { sleep quality by the Pittsburgh } \\
\text { Sleep Quality Inventory; sleep } \\
\text { hygiene instructions. }\end{array}$ & 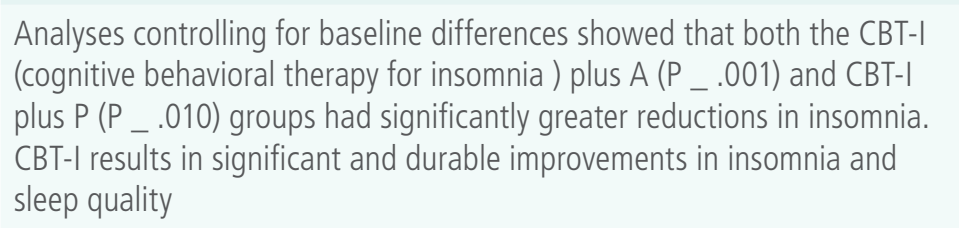 \\
\hline Rogers & (2015) Levels of Evidence:1.a & $\begin{array}{l}\text { Pilot randomized } \\
\text { controlled trial }\end{array}$ & $\begin{array}{l}\text { Forty-six postmenopausal } \\
\text { BCS ( } \leq \text { Stage II, off primary } \\
\text { treatment) were randomized } \\
\text { to a 3-month exercise } \\
\text { intervention or control group. }\end{array}$ & $\begin{array}{l}\text { PSQI and PROMIS®), objective } \\
\text { sleep quality (accelerometer), } \\
\text { serum cytokines, } \\
\text { accelerometer physical activity, } \\
\text { cardiorespiratory fitness, body } \\
\text { composition, fatigue, and } \\
\text { psychosocial factors. }\end{array}$ & $\begin{array}{l}\text { When compared with control, the intervention group demonstrated a } \\
\text { significant increase in PSQI sleep duration (i.e., fewer hours of sleep/night) } \\
\text { ( } d=0.73, p=.03 \text { ). Medium to large but non-significant standardized effect } \\
\text { sizes were noted for PSQI daytime somnolence ( } d=-0.63, p=.05 \text { ) and } \\
\text { accelerometer latency ( } d=-0.49, p=.14) \text {. } \\
\text { Inflammation and psychosocial factors may mediate or enhance sleep } \\
\text { response to our exercise intervention. Further study is warranted to } \\
\text { confirm our results }\end{array}$ \\
\hline Lengacher & (2015) Levels of Evidence: 1.a & $\begin{array}{l}\text { randomized } \\
\text { controlled }\end{array}$ & $\begin{array}{l}\text { Seventy-nine BCS } \\
\text { participants }\end{array}$ & $\begin{array}{l}\text { sleep diaries and the Pittsburg } \\
\text { Sleep Quality Index (PSQI)) and } \\
\text { objective sleep parameters (OSP) } \\
\text { (i.e., actigraphy) were measured } \\
\text { at baseline, six weeks and } 12 \\
\text { weeks after completing the } \\
\text { MBSR(BC) or UC program. }\end{array}$ & $\begin{array}{l}\text { Results showed indications of a positive effect of MBSR(BC) on OSP at } 12 \\
\text { weeks on sleep efficiency } \\
\text { These data suggest that MBSR(BC) may be an efficacious treatment to } \\
\text { improve objective and subjective sleep parameters in BCS. }\end{array}$ \\
\hline
\end{tabular}

* Levels of Evidence is developed by the Joanna Briggs Institute Levels of Evidence and Grades of Recommendation Working Party October 2013 [13]. 
Table 2. Levels Of Evidence For Effectiveness BY JBI.

\begin{tabular}{|c|c|}
\hline \multicolumn{2}{|l|}{ Level 3} \\
\hline Observational & Analytic Designs \\
\hline a & Systematic review of comparable cohort studies \\
\hline b & $\begin{array}{l}\text { Systematic review of comparable cohort and other } \\
\text { lower study designs }\end{array}$ \\
\hline c & Cohort study with control group \\
\hline$d$ & Case - controlled study \\
\hline e & Observational study without a control group \\
\hline
\end{tabular}

\begin{tabular}{l|l}
\multicolumn{1}{|c|}{ Level 1} & \multicolumn{1}{c}{ Analytic Designs } \\
\hline \multicolumn{1}{c|}{ Observational } & \multicolumn{1}{c}{ Randomized Controlled Trials (RCTs) } \\
\hline a & RCTs and other study designs \\
b & RCT \\
\hline c & Pseudo-RCTs \\
\hline d &
\end{tabular}

\section{Characteristics of the Studies}

A variety of journals has published articles on sleep quality in breast cancer patients over the last years. The largest number of articles was found in the Psycho-Oncology Journal and in the Journal of Pain Symptom Management, with 3 articles each. There were articles published in several international oncology journals such as the European Journal of Oncology Nursing and Cancer Nursing, as well as in more general publications such as Psychology and Health. Regarding the year of publication, 5 articles were published in 2009, 2 in 2010, 3 in 2011, 4 in 2012, 2 in 2013, 8 in 2014 and 3 in 2015.

Nurse investigators, including five PhD prepared lead authors, contributed to a majority of the studies. The participation of undergraduate nursing students is noted in 2 articles [14, 15]. Inter-professional collaboration in researches is important, and this was evident in the majority of these articles with contributions from medicine, nursing, and psychology.

All studies in this review utilized a quantitative methodology, with 13 cross-sectional studies and 20 longitudinal studies. We emphasize the impor- tance of longitudinal studies because analyzing the patient in 2 or more stages of treatment and documenting the difference in quality of sleep, may be helpful to nurses in managing their patients care. Nine articles reported randomized clinical trials [8, $10,16-21]$ and 3 were a secondary analysis [4, 2223].

In the studies selected for this review, the most common instrument used for data collection was the Pittsburgh Sleep Quality Index (PSQI) in 9 studies $[2-4,6,9,10,14-17,19-22,24,25]$, followed by actigraphy in 7 studies [6, 17, 18, 22, 25-27] , sleep diaries in 6 studies [6, 17, 18, 22, 25-27] and general questions in 1 study [15].

\section{How Is the Sleep Quality in Women with Breast Cancer?}

All 27 studies in this review found a significant level of sleep disturbance in women with breast cancer at various stages in their treatment. A summary of the findings is in Table 1.

Studies using the PSQI documented poor sleep quality for $65 \%$ to $70 \%$ of the participants $[4,28]$ and, actigraphy verified that up to $87 \%$ of the sample had an excessive number of awakenings.13Moreover, sleep diary records identified that difficulty maintaining sleep was evident by the higher than normal (2-6) number of awakenings per night (6-12) [27].

Common sleep-time complaints noted in all of these studies is time spent in bed without sleeping, difficulty returning to sleep, decreased nocturnal sleep duration, increased sleep latency and waking earlier than desired. Additionally, the associated wake-time symptoms of sleepiness, fatigue, increased naps, cognitive impairment, and performance are also prevalent.

Mosher and Duhamel report that $70 \%$ of the patients completing the PSQI had scores greater than the cutoff point of five, indicating significant decrements in sleep quality [28]. In a longitudinal study, more than $85 \%$ of the patients had a high number of nighttime awakenings [16]. When comparing wo- 
men with cancer-related fatigue and postmenopausal women without cancer, the authors found that breast cancer patients showed significantly more sleep difficulties [27]. These sleep problems were characterized by prolonged sleep onset latency $(M=$ 54.3, $S D=49.2$ minutes) and frequent nighttime awakenings, despite $40 \%$ of the patients using sleep medications three or more times a week [16]. Greater ongoing fatigue or sleep disturbance predicted a slower cortisol decline, and longer sleep latency predicted both a greater cortisol linear decline and slower cortisol decline [9].

Several studies elucidate how the sleep quality changed during cancer treatments such as chemotherapy or radiotherapy. Considering the PSQI score $>5$ that represents poor quality sleep, [29] found that $65 \%$ of women self-reported poor sleep in the month preceding chemotherapy. Subjective sleep quality was poor at baseline and remained unchanged throughout treatment [3]. Half of the survivors reported no sleep duration change over time; however, 25\% reported sleep changes indicating a temporary (5.6\%), late-occurring (14\%), or sustained (5.9\%) change [15]. Patients reported poor quality of life and poor sleep quality before and during chemotherapy with short sleep time and long naps recorded at both time points [26].

Prior to chemotherapy, participants' related mild fatigue, and poor sleep quality; after an intervention using behavior therapy, they perceived increased sleep quality [27]. On Cycle-4 chemotherapy, the breast cancer patients showed worse sleep, increased fatigue and more depressive symptoms, compared to their baseline levels [6].

A study suggests that disturbed sleep before and after a chemotherapy infusion exacerbates fatigue and anxiety [30]. Authors concluded that reducing sleep disturbance may be an important way to improve quality of life during chemotherapy [30].

Other studies reported using an intervention and the authors concluded that future work might consider integrating sleep and fatigue content into stress management interventions for women with early-stage breast cancer [20]. Compared to usual care, eletro acupuncture produced significant improvement in fatigue, anxiety and depression [21]. The cognitive behavioral therapy for insomnia was used and showed durable improvements in insomnia and sleep quality [19].

A few researchers compare the sleep quality in those with breast cancer to other types of cancer. For instance, 2 articles compare women with breast cancer $(\mathrm{BC})$ and men with prostate cancer (PC). Both $B C$ and $P C$ patients report the most sleep problems prior to and during chemotherapy. [14] The occurrence rates for sleep disturbance and fatigue were significantly higher in patients with breast cancer as compared to prostate cancer [2].

Future work may consider integrating sleep and fatigue content into stress management interventions for women with early-stage breast cancer [20].

\section{What Health Issues Are Associated with Poor Quality Sleep in Women with Breast Cancer?}

Poor sleep quality is reported in all 27 studies and is associated with several health issues such as severe fatigue, depression, anxiety, hot flashes, pain, and generally poorer quality of life. A significant relationship between fatigue and sleep disturbances was found in 3 studies $[2,3,9,2,3,28,30]$ and higher scores on the PSQI predicted membership in the higher fatigue group for general and physical fatigue. [31]

Participants with breast cancer self-reported significantly higher levels of sleep disturbance $(P=.008)$ and fatigue $(P=.005)$ than patients with prostate cancer [2]. Fatigue was significantly associated with subjective reports of poor sleep and objective measures of daytime sleepiness; however, not with nocturnal sleep as measured by actigraphy [3]. Additionally, there is a high prevalence of distress, sleep problems, and fatigue across demographic 
and medical subgroups of metastatic breast cancer patients [28].

The relationship between fatigue and sleep has been reported in other studies [12, 32]. Fatigue was significantly correlated with subjective and objective measures of sleep in women with breast cancer [8]. Women with insomnia also reported significantly higher levels of depression, anxiety and fatigue [33].

Studies identify a significant relationship between sleep quality and mental health disorders including depression and anxiety [21, 22, 24-25, 34]. One group of researchers that investigated if breast cancer survivors (BCS) with insomnia can be grouped according to their level of fatigue discovered significant differences in insomnia severity, anxiety, depression, and quality of life among the subgroups of exhausted, tired and restored [22].A study of prevalence, severity, and correlates of sleep-wake disturbances compares long-term breast cancer survivors (BCS) to age-matched women without breast cancer (WWC) and finds significant correlates of prevalence with poor sleep for BCS including hot flashes, poor physical functioning, depressive symptoms and distress [24].

The authors identify that comorbidity, evening fatigue, and depressive symptoms predicted baseline levels of subjective sleep disturbance, and that depressive symptoms predicted the trajectory of subjective sleep disturbance [25]. Worse Physical Component scores were associated with reports of poor sleep and less recorded nap time, suggesting sleep plays an important role in cancer patients' quality of life [8].

\section{Discussion}

Our review findings expose the overlooked disorders of sleep in women with breast cancer and the associations with cancer-related fatigue (CRF), depression and other important health issues. Furthermore, these 27 studies consistently document the high prevalence of poor sleep quality and decrease in quality-of-life. To begin to address this important patient care issue, we recommend use of tools like the PSQI, actigraphy and sleep diary for identification and assessment of sleep quality in women with breast cancer.

Comparisons between women with and without cancer revealed that breast cancer survivors had significantly higher PSQI global scores, indicating poorer sleep quality, as compared to women without breast cancer [24]. Another study comparing 30 fatigued female breast cancer chemotherapy outpatients and 32 non-cancer postmenopausal fatigued patients found a significantly longer sleep latency in the breast cancer group. Forty-seven percent of CRF patients expressed "severe difficulty" with sleep latency, while $25 \%$ of postmenopausal women were in this category [16]. Additionally, women's menopausal status when starting chemotherapy was associated with differing patterns of sleep and hot flashes over time [4].

The grouping or "clustering" of cancer-related symptoms has been highlighted in recent reports as an important priority for nursing research. Greater knowledge is needed regarding the interaction of multiple symptoms and their potential impact on cancer patient outcomes if advances are to be realized in caring for persons diagnosed with cancer. The studies in this review inform health care professionals to proactively assess for the continued presence of multiple symptoms once treatment has ended, with an understanding that a single, intense symptom rarely occurs. Moreover, the focus of care should target the symptom interactions, and their association with quality of life. Those caring for cancer patients need to overcome the outdated practice of managing pain, fatigue, depression or poor sleep quality as isolated symptoms by concurrently assessing and managing these related health problems [12, 22]. Tools such as PSQI, actigraphy and sleep diary can assist health professionals to assess the sleep quality of their female breast cancer patients. 
The PSQI is a patient questionnaire designed to evaluate the subjective sleep quality and disturbances that have been present during the past month. This questionnaire, which has been validated in several countries and languages, contains 19 items that can be self-administered or employed in an interview, and 5 questions to be answered by roommates. The latter 5 questions are used only for information and are not scored. The 19 questions are grouped into seven sleeprelated components comprising quality, latency, duration, efficiency, disturbances, use of sleeping medication, and daytime sleepiness. The score of each component ranges from zero to three points. The overall score is obtained with the sum of components, ranging from zero to 21 points. The higher the value obtained, the poorer sleep quality with the overall score of five points as the cut off for distinguishing between poor sleep quality (higher than five points) from good sleep quality (five points or less) [29].

Actigraphy is a technique for recording a persons sleep-wake pattern through recording of limb movements for a 24-hour cycle. This device is placed on the wrist of the non-dominant limb and detects motion, thus recording rest and activity. It provides data for interpretation in order to infer the presence of sleep or wakefulness. Frequent movements are interpreted as wakefulness, and low movements as sleep. It provides data on total sleep time, total time awake, number of awakenings, and sleep latency $[35,36]$. This objective measure records sleep and awake patterns. This tool is helpful to the health care professional as an adjunct to the PSQI and sleep diary; although, not commonly found in use outside of a sleep disorders center.

Another means of assessing sleep patterns and sleep quality is a sleep diary, which is often used with actigraphy. This diary is usually completed for 14 days by the patient to document sleep patterns, subjective sleep of quality and behaviors affecting sleep [8]. documented that this tool could be used to obtain reliable data about home sleep/wake patterns in women undergoing chemotherapy for breast cancer.

Studies in this review consistently found that poor sleep quality is experienced by female breast cancer patients. Nurses assess the responses that patients have to disease in order to select and implement interventions to improve their quality of life. Because poor sleep quality is a frequent complaint of women with breast cancer and decreases their quality of life, it is essential to routinely assess for sleep disruptions and intervene. The nurses' evaluation of sleep quality should include the associated symptoms discovered in these studies that may be clustered with pain, fatigue, depression and others. And just one base population study was found on this study, it is necessary more future studies [37].

The sleep disturbances often become chronic and nurses need to make recommendations and to treat them because sleep disturbances are common among breast cancer survivors, even after completion of active cancer treatment, we need to be proactive to avoid the worst problems after treatment [10].

Interventions studies are very important and authors concluded MBSR may be an efficacious treatment to improve objective and subjective sleep parameters in breast câncer patients [17]. In another study, when compared with controls, the intervention group demonstrated a significant increase in sleep duration with MBSR [18].

However, it is important to note that often the poor quality of sleep gets little attention from patients, who regard it as a "normal" consequence of the treatment. Despite the latest knowledge on this topic, many health care professionals do not identify and treat their patients' sleep problems. If untreated, many sleep disorders can become chronic health problems in patients with cancer, persisting after treatment of the disease. Furthermore, attention should be paid to the importance of 
quality-of-life that has been frequently explored in the literature and encompasses sleep.

\section{Limitations}

There is a possibility that relevant articles were missed by this review. Future reviews are necessary to expand knowledge about the relationships between sleep quality, fatigue, depression, and pain in women with breast cancer.

\section{Implications for Practice}

An important aspect of nursing care for breast cancer patients is assessment for associated health problems, which includes sleep quality. We recommend the use of validated screening tools such as the PSQI and sleep diary to assess for sleep disturbances. This assessment should be done at several key points in the cancer care process including the initial encounter prior to diagnosis, at diagnosis, during treatment, at the end of treatment, and at follow-up.

Furthermore, we recommend that nurses increase their knowledge of normal and abnormal sleep to better assess for disorders, counsel their patients, and refer for further evaluation and management. Through regular assessment of sleep quality, nurses can promote additional improvements in the quality-of-life for cancer patients.

\section{Conclusions}

This review is relevant in view of the increased incidence of breast cancer and the high prevalence of sleep disorders Assessing and identifying sleep problems in cancer patients should be a priority, as the disease is debilitating, and compromised sleep quality may further decrease functional ability. The negative effects of poor sleep quality can exacerbate other cancer-related symptoms and persist long after the end of treatment. We recommend that researchers focusing on breast cancer care should study the effectiveness of interventions that target the symptom cluster of poor sleep quality, pain, fatigue, and depression to decrease the burden of this devastating disease.

\section{References}

1. Brazil. Ministry of Health. Department of Health Care. National Cancer Institute. Coordination and Monitoring of Cancer Prevention. Estimates 2014: Incidence of Cancer in Brazil. Rio de Janeiro: INCA, 2014.

2. Garrett K, Dhruva A, Koetters T, et al. Differences in sleep disturbance and fatigue between patients with breast and prostate cancer at the initiation of radiation therapy. J Pain Symptom Manage. 2011; 42(2):239-250.

3. Liu L, Rissling M, Natarajan L, et al. The longitudinal relationship between fatigue and sleep in breast cancer patients undergoing chemotherapy. Sleep. 2012; 35(2):237-245.

4. Beck SL, Berger AM, Barsevick AM, Wong B, Stewart KA, Dudley WN. Sleep quality after initial chemotherapy for breast cancer. Supportive Care in Cancer: official journal of the Multinational Association of Supportive Care in Cancer. 2010; 18(6):679-689.

5. Palesh O, Aldridge-Gerry A, Zeitzer JM, Koopman C, Neri E, Giese-Davis J, Jo B, Kraemer H, Nouriani B, Spiegel D. Actigraphymeasured sleep disruption as a predictor of survival among women with advanced breast cancer. SLEEP 2014; 37(5):837-842.

6. Ancoli-Israel S, Liu L, Rissling M, Natarajan L, Neikrug AB, Palmer BW. Sleep, fatigue, depression, and circadian activity rhythms in women with breast cancer before and after treatment: a 1-year longitudinal study. Supportive Care in Cancer, 2014; 22(9), 2535-2545

7. Faraut B, Boudjeltia $K Z$, Dyzma $M$, et al. Benefits of napping and an extended duration of recovery sleep on alertness and immune cells after acute sleep restriction. Brain Behavior and Immunity. 2011; 25(1):16-24.

8. Liu L, Mills PJ, Rissling M, et al. Fatigue and sleep quality are associated with changes in inflammatory markers in breast cancer patients undergoing chemotherapy. Brain Behav Immun. 2012; 26(5):706-713.

9. Tell D, Mathews HL, Janusek LW. Day-to-day dynamics of associations between sleep, napping, fatigue and the cortisol diurnal rhythm in women diagnosed with breast cancer. Psychosomatic medicine, 2014; 76(7), 519-528. doi:10.1097/ PSY.0000000000000097. 
10. Chen WY, Giobbie-Hurder A, Gantman K, Savoie J, Scheib $R$, Parker LM,et al. A randomized, placebo-controlled trial of melatonin on breast cancer survivors: impact on sleep, mood, and hot flashes. Breast cancer research and treatment, 2014; 145(2), 381-388.

11. Furlani R, Ceolim MF. Sleep quality of women with gynecological and breast cancer. Rev. Latino-Am. Enfermagem. 2006; 14(6):872-878.

12. Mansano-Schlosser T, Ceolim M, Filomena. Factors associated with sleep quality in the elderly receiving chemotherapy. Rev. Latino-Am. Enfermagem. 2012; 20(6):1100-1108.

13. The Joanna Briggs Institute Levels of Evidence and Grades of Recommendation Working Party [Internet]. October 2013. New JBI levels of evidence by The Joanna Briggs Institute. Disponible en: http://joannabriggs.org/assets/docs/approach/JBI-Levels-ofevidence 2014.pdf Consultado en octubre 2015.

14. Thomas KS, Bower J, Hoyt MA, Sepah S. Disrupted sleep in breast and prostate cancer patients undergoing radiation therapy: The role of coping processes. Psycho Oncol. 2010; 19(7):767-776.

15. Alfano CM, Lichstein KL, VanderWal GS, et al. Sleep duration change across breast cancer survivorship: Associations with symptoms and health-related quality of life. Breast Cancer Res Treat. 2011; 130(1):243-254

16. Wu H, Davis JE, Padiyar JP, Yarandi H. A comparison of disrupted sleep patterns in women with cancer-related fatigue and postmenopausal women without cancer. European journal of oncology nursing: the official journal of European Oncology Nursing Society. 2011; 15(4):318-324.

17. Lengacher $C A$, Reich $R R$, Paterson $C L$, Jim HS, Ramesar $S$, Alinat $C B$, et al. The effects of mindfulness-based stress reduction on objective and subjective sleep parameters in women with breast cancer: a randomized controlled trial. Psycho-Oncology. 2015; 24(4), 424-432.

18. Rogers LQ, Fogleman A, Trammell R, Hopkins-Price P, Spenner $A$, Vicari $S$, et al. Inflammation and psychosocial factors mediate exercise effects on sleep quality in breast cancer survivors: pilot randomized controlled trial. Psycho-Oncology, 2015; 24(3), 302310.

19. Roscoe JA, Garland SN, Heckler CE, Perlis ML, Peoples AR, Shayne $\mathrm{M}$, et al.Randomized placebo-controlled trial of cognitive behavioral therapy and armodafinil for insomnia after cancer treatment. Journal of Clinical Oncology, 2014; JCO-2014.165171.

20. Vargas S, Antoni MH, Carver CS, Lechner SC, Wohlgemuth W, Llabre M,et al. Sleep quality and fatigue after a stress management intervention for women with early-stage breast cancer in Southern Florida. Int. J. Behav. Med, 2014: 21(6), 971 981. doi:10.1007/s12529-013-9374-2
21. Mao JJ, Farrar JT, Bruner D, Zee J, Bowman M, Seluzicki C,et al. Electroacupuncture for fatigue, sleep, and psychological distress in breast cancer patients with aromatase inhibitorrelated arthralgia: A randomized trial. Cancer, 2014; 120(23), 3744-3751.

22. Dirksen SR, Belyea MJ, Epstein DR. Fatigue-based subgroups of breast cancer survivors with insomnia. Cancer Nurs. 2009; 32(5):404-411.

23. Berger AM, Marunda H, Agrawal S. Influence of menopausal status on sleep and hot flashes throughout breast cancer adjuvant chemotherapy. JOGNN. 2009; 38(3):353-366.

24. Otte JL, Carpenter JS, Russell KM, Bigatti S, Champion VL. Prevalence, severity, and correlates of sleep-wake disturbances in long-term breast cancer survivors. J Pain Symptom Manage. 2010; 39(3):535-547.

25. Dhruva A, Paul SM, Cooper BA, et al. A longitudinal study of measures of objective and subjective sleep disturbance in patients with breast cancer before, during, and after radiation therapy. J Pain Symptom Manage. 2012; 44(2):215-228.

26. Liu $L$, Fiorentino $L$, Rissling $M$, Natarajan $L$, Parker $B A$, Dimsdale $J E$, et al. . Decreased health-related quality of life in women with breast cancer is associated with poor sleep. Behavioral sleep medicine ,2013; 11(3), 189-206.

27. Berger AM, Kuhn BR, Farr LA, et al. Behavioral therapy intervention trial to improve sleep quality and cancer-related fatigue. Psycho Oncol. 2009; 18(6):634-646.

28. Mosher CE, Duhamel KN. An examination of distress, sleep, and fatigue in metastatic breast cancer patients. Psychooncology. 2012; 21(1):100-107.

29. Beck SL, Schwartz AL, Towsley G, Dudley W, Barsevick A. Psychometric evaluation of the pittsburgh sleep quality index in cancer patients. J Pain Symptom Manage. 2004; 27(2):140-148.

30. Ratcliff CG, Lam CY, Arun B, Valero V, Cohen L. Ecological momentary assessment of sleep, symptoms, and mood during chemotherapy for breast cancer. Psycho-Oncology, 2014; 23(11), 1220-1228.

31. Banthia R, Malcarne VL, Ko CM, Varni JW, Sadler GR. Fatigued breast cancer survivors: The role of sleep quality, depressed mood, stage and age. Psychol Health. 2009; 24(8):965-980.

32. Zee PC, Ancoli-Israel S, Workshop Participants. Does effective management of sleep disorders reduce cancer-related fatigue? Drugs. 2009; 69 Suppl 2:29-41. 
33. Garland S,N, Palmer C, Donelson M, Gehrman P, Johnson FB, et al. A nested case-controlled comparison of telomere length and psychological functioning in breast cancer survivors with and without insomnia symptoms. Rejuvenation research, 2014; 17(5), 453-457.

34. Aldridge-Gerry A, Zeitzer JM, Palesh OG, Jo B, Nouriani B, Neri E, Spiegel D. Psychosocial correlates of sleep quality and architecture in women with metastatic breast cancer. Sleep medicine, 2013; 14(11), 1178-1186.

35. Mystakidou K, Parpa E, Tsilika E, et al. The relationship of subjective sleep quality, pain, and quality of life in advanced cancer patients. Sleep. 2007; 30(6):737-742.

36. Palesh O, Aldridge-Gerry A, Zeitzer JM, Koopman C, Neri E, Giese-Davis J, Jo B, Kraemer H, Nouriani B, Spiegel D. Actigraphymeasured sleep disruption as a predictor of survival among women with advanced breast cancer. SLEEP 2014; 37(5):837-842.

37. Girschik J, Heyworth J, Fritschi L. Self-reported sleep duration, sleep quality, and breast cancer risk in a population-based casecontrol study. American journal of epidemiology, kws422. Am J Epidemiol. 2013; 177(4):316-327

Publish in International Archives of Medicine

International Archives of Medicine is an open access journal publishing articles encompassing all aspects of medical science and clinical practice. IAM is considered a megajournal with independent sections on all areas of medicine. IAM is a really international journal with authors and board members from all around the world. The journal is widely indexed and classified Q2 in category Medicine. 